\title{
Social network influences and the adoption of obesity-related behaviours in adults: a critical interpretative synthesis review
}

\author{
Nestor Serrano Fuentes ${ }^{*}$, Anne Rogers and Mari Carmen Portillo
}

\begin{abstract}
Background: Obesity is a key risk factor for developing a long-term condition and a leading cause of mortality globally. The limited evidence associated with interventions that currently target obesity-related behaviours demand new approaches to tackle this problem. Given the evidence that social ties are implicated in the gaining and reduction of weight, the use of social networks in interventions is potentially a novel and useful means of tackling this health issue. There is a specific gap in the literature regarding what and how social network properties and processes together with environmental and individual factors influence the adoption of positive and negative obesity-related behaviours in adults.
\end{abstract}

Methods: To address this gap in developing an integrated and holistic conceptual approach, a critical interpretative synthesis was undertaken following a line of argument synthesis as an analytical strategy.

Results: Twenty-four studies were included. The data-driven themes meso-micro network processes, contextual and individual factors, and types of ties and properties were identified individually as components and causes of different health scenarios. Nevertheless, these drivers do not act on their own. As a consequence, developing multi-agent coalitions considering cross-level influences between the data-driven themes are two mechanisms that are created to understand more in-depth how social networks and the environment influence the adoption of obesity-related behaviours. These two new constructs point to a dynamic multilevel set of influences between multiple constructs, developing scenarios where positive and negative health results are identified.

Conclusions: This critical interpretative synthesis offers a new means of exploring the application of social network properties and mechanisms in the 'obesity' field. The synthesizing argument created during the analysis process might be considered by health policy-makers, who might need to contemplate the wider open system of socially connected individuals and harness these forces to design new interventions where social networks and other contextual and individual factors operate together in a complex multilevel environment influencing obesity-related behaviours and practices.

Keywords: Social networks, Obesity, Health behaviours, Critical interpretative synthesis review

\footnotetext{
* Correspondence: N.Serrano-Fuentes@soton.ac.uk

NIHR CLAHRC Wessex. School of Health Sciences, University of Southampton,

Building 67, University Road, Southampton SO17 1BJ, UK
}

(c) The Author(s). 2019 Open Access This article is distributed under the terms of the Creative Commons Attribution 4.0 International License (http://creativecommons.org/licenses/by/4.0/), which permits unrestricted use, distribution, and reproduction in any medium, provided you give appropriate credit to the original author(s) and the source, provide a link to the Creative Commons license, and indicate if changes were made. The Creative Commons Public Domain Dedication waiver (http://creativecommons.org/publicdomain/zero/1.0/) applies to the data made available in this article, unless otherwise stated. 


\section{Background}

Obesity is a leading public health challenge in developed and developing countries. It has reached epidemic proportions globally, with at least 2.8 million people dying each year as a result of being affected by overweight or obesity [1] and represents a key risk factor of developing a long-term condition (LTC) [2]. The estimated prevalence of individuals with obesity has increased from 921 million in 1980 to 2.1 billion in 2013 [3]. In 2016, 39\% of adults aged 18 years and over had overweight and $13 \%$ obesity [4]. There are variations in incidence between countries with higher levels estimated in the United Kingdom (UK) and United States (USA) (38.2\% of adults in the USA [5] and $24.8 \%$ in the UK [6]. The rise in incidence (three-fold over thirty years) has led to an increase in health services expenditure. For example, in the National Health System (NHS) the costs of treating overweight and obesity have increased from $£ 479.3$ million in 1998 to $£ 4.2$ billion in 2007 [7]. In relation to LTCs in the United Kingdom, 70\% of total health costs account for this health issue [8].

A number of interventions have been designed to address obesity and overweight prevalence with the most common of these targeting obesity-related behaviours (ORBs), specifically, unhealthy food and drink choices (including alcohol), eating larger than average portions of food and a lack of physical activity [9-11]. However, a substantial number of individuals fail to adhere sustainably to these weight loss actions [12] suggesting that new approaches need to be considered to assist individuals to engage in healthy behaviours and practices in support of long-term weight loss. These approaches might usefully incorporate an understanding of the complex social and contextual influences of obesity [7, 13, 14]. Possible influences include food production, food consumption, societal influences, individual psychology and activities, activity environment and the linkages between them.

Social relationships are considered to be relevant mediators operating in open systems of a tangled and complex set of events, contexts, resources, practices, and priorities [15]. The networks of people assist in the identification of the nuanced ways in which the management of health-related practices can be integrated into open systems. Thus, people in contemporary society are mutually dependent upon one another, and relationships and connections in personal communities have considerable potential positive and negative influences on individual's behaviours. For example, snacking habits might be shared by socially connected individuals across friends, spouses and sibling peers supporting evidence of collective behavioural process impacting on eating practices [16]. Social relationships can also influence health positively, bringing into play 'protective' effects. For example, in terms of physical activity, adolescent girls who have more physically active friends report higher activity levels themselves [17]. Koetsenruijter et al. [18] indicate that larger support relationships show a positive association with selfmanagement skills in patients with diabetes, and therefore logically this applies to people with ORBs. An in-depth understanding of these relations might be useful from which to consider the design of interventions and approaches to improving obesity-related behaviours, health outcomes and associated reducing in the costs of health service utilisation. Thus, to study these potentially meaningful relationships, a network approach [19] that provides the epistemological, ontological and methodological perspective from which to understand social networks (a set of people linked to one another by specific relationships) can be applied [20]. Four dimensions of social networks are of relevance here -structure, function, strength and content [21]. The first of these considers the structural aspect of networks, including the patterns of linkages between actors [21]. Network function determines the type of exchanges, services, or supports accessible through relationships [21] whilst network strength describes the intensity and durability of ties between individuals within the network [22]. Network content refers to attitudes, emotions and behaviours flowing between network members [23]. Thus, network effects (e.g. health outcomes) are a function of interactions between these four dimensions [18].

There has been conceptual and empirical attention paid to the impact of social networks on health $[24,25]$. Specifically, in terms of social networks and obesity, most of the research has focused on exploring spread, - differentiating relevant processes such as social selection, social influence and confounding effects (using mainly quantitative approaches [26]. Other authors have studied how social networks and social norms for unhealthy eating and inactivity might be associated with obesity treatments outcomes in adults [27]. Nevertheless, few network-mediated interventions have been developed to address obesity specifically. Currently, the most relevant are targeting influential individuals to spread healthy information and behaviours through interpersonal ties [28, 29] and creating opportunities for health-supportive relationships to be maintained [29-31]. In building this nascent network focus in the field, it is necessary to unpack more of the mechanisms by which social networks influence obesity with a view to developing network-based obesity interventions that alter, nurture or harness these mechanisms [32]. In order to understand how social networks affect ORBs, environmental-difference effects need to be considered [33] and understood as operating at multiple levels [34, 35]. A multilevel network perspective identifies principles that enable a more integrated understanding of phenomena that unfold within and across levels $[33,36]$. Therefore, the identification, classification and integration of all these factors at 
different levels might develop pathways in which they are dynamically related in order to influence the adoption of positive and negative ORBs in adults and have the basis to create public health-policy relevant interventions.

The specific gap regarding what and how network properties and processes together with other factors produce positive and adverse health outcomes in adults with ORBs has been addressed to a limited extent previously [37-39]. However, there is a specific need to focus on both positive and negative results $[40,41]$ and for multilevel approaches to be bridged to create an integrated theory, specifying relationships between phenomena. Thus, this review aims to understand what and how social network properties and processes together with environmental-difference effects influence the adoption of healthy and unhealthy ORBs in adults.

\section{Methods}

The complexity that surrounds the understanding of how social networks influence the adoption of ORBs requires the synthesis and interpretation of many types of different research evidence. Thus, it was decided to use a critical interpretative synthesis (CIS) as a review method, since it involves induction and interpretation of qualitative, quantitative and mixed-method data, and is primarily conceptual in process and outcome [42]. Mathematical and quantitative research powerfully describes the structure of networks and documents whether their effects are significant or not, in a statistical and theoretical sense [21]. The qualitative research presents the processes of network process and functioning, that is to say, how these networks are created [21] and what resources are transferred between them within a specific context [20].

The induction and interpretation of these data is contrary to the conventional systematic reviews which are developed as a specific methodology for assembling, pooling and summarising data [42]. Thus, this CIS aimed to generate concepts and theory where those concepts could be integrated and interpreted rather than summarising data per se. Another advantage for our research interests is that a CIS also has flexibility and is convenient in terms of appraising quality, using relevance (e.g. likely contribution to theory development) rather than methodological characteristics as a means of determining the 'quality' of individual papers [43]. In comparison with other methods of interpretative synthesis (e.g. meta-ethnography or grounded theory), a CIS does not only use qualitative research and, also, is distinct in its 'explicit orientation' towards theory generation [44], following an analysis process of different phases for the interpretation and integration of the data and, therefore, providing a more insightful way of understanding a phenomenon. The generation of a more detailed and higher-order structured theoretical framework might be useful to identify potential healthy and unhealthy scenarios.

\section{Search strategy}

The search strategy was built around several bibliographic databases: CINAHL, Cochrane, EMBASE, Ovid, PsycINFO, Pubmed, Sociological Abstracts and Web of Science. To avoid the risk of missing relevant information, other strategies have been used to fit better with the exploratory nature of the aim [42]. This includes hand searches (between 2000 and 2017) of some key journals (e.g. Obesity, Obesity Reviews, The Annual Review of Public Health, The Annual Review of Sociology and Behavioural Medicine). The publication of relevant articles regarding social networks and obesity and social networks and health in these journals motivated the undertaking of specific hand searching [25-27, 32, 37, 45]. The time interval chosen was the year 2000 as there are relevant seminal papers from this date. The authors applied a citation snowballing technique to generate lists of related articles regarding the aim. Finally, specific websites were searched to identify epidemiological information related to obesity and overweight worldwide with a specific focus to the UK context, causes, prevention, obesity-related problems, relationship to prevention and management of long-term conditions, its economic impact on health systems and research institutions that are interested in social networks and obesity. These websites are Public Health England, The Global Obesity Prevention Center in Johns Hopkins Bloomberg School of Public Health, The National Institute for Health and Care Excellence, Yale Institute for Network Science and World Health Organization.

\section{Key terms}

Four main terms were developed to cover the key elements of the aim of this review: obesity, long-term conditions, social networks and health behaviours (see Table 1). Diabetes-related terms were included in the list of terms connected with LTCs. The reason for this was that we found several articles regarding how social networks influence diabetes and that diabetes and obesity have several health behaviours in common, such as diet and physical activity. Also, other terms pertaining to obesity were considered but omitted finally in the search strategy such as 'body fat', 'adiposity', 'body weight', 'energy intake', 'caloric intake' or 'nutrition'. This was because the focus was more on a sociological approach rather than a biomedical one. A combination of 'all field' search terms of each facet was undertaken to avoid missing relevant information. We applied truncations, acronyms and the booleans OR and AND to combine terms within each column and between columns from Table 1 . 
Table 1 Search strategy: key terms

\begin{tabular}{llll}
\hline Obesity & Long-term conditions & Social networks & Health behaviours \\
\hline Obese & Chronic illness* & Networks & Diet \\
Obesity & Chronic disease* & Network intervention* & Exercise \\
Overweight & Chronic condition* & Peer* & Food choice \\
& T2DM & Health behav* & Health behav* change \\
& DM & Social embeddedness & Health behav* intervention \\
& DM2 & Social influence* & Physical activity \\
& Diabetes & Social network* & Weight loss \\
& Diabetic & Social relationship* & \\
& Long-term condition* & Social support & \\
& & \\
& LTC & & \\
& Type 2 diabet* & & \\
\hline
\end{tabular}

The asterisk indicates the possible endings of some words.

\section{Screening}

Limits were used to search the online databases: articles published in English and Spanish languages, the year of publication (between 2000 and 2017) and age groups (all adults and 19 plus years). The inclusion criteria set initially were: (i) empirical studies (qualitative, quantitative and mixed-methods) exploring the influence of relationships on the adoption of ORBs; (ii) review studies and grey literature (policy/organizational documents, conferences, abstracts). The exclusion criteria were: (i) papers that did not mention terms related to 'relationships', 'social networks' and 'ties' in the title or abstract; (ii) articles focused on LTCs in which ORBs were not mentioned. Eligibility of the papers was performed analysing titles and abstracts. Full papers were retrieved for independent assessment when the title and abstract appeared to meet all inclusion criteria, or when suitability could not be judged by title and abstract.

\section{Quality assessment and data extraction}

The integration of relevance and rigor was essential in the selection of articles. 'Rigor' proposes that literature needs methodological credibility to address the main aim [46]. Dixon-Woods et al. [47] recommendations were followed to ensure quality assessment of the studies vis:

1. Are the aims and objectives of the research clearly stated?

2. Is the research design clearly specified and appropriate for the aims and objectives of the research?

3. Do the researchers provide a clear account of the process by which their findings were reproduced?

4. Do the researchers display enough data to support their interpretations and conclusions?

5. Is the method of analysis appropriate and adequately explicated?

Standardized data extraction templates were created to represent and make more visible data from the qualitative, mixed-methods and quantitative studies (see Table 2).
They included information regarding paper reference and setting, Dixon-Woods et al. [42] appraisal prompts, methodological strengths, focus (aim) and main findings related to our research interests to illustrate the process followed.

\section{Synthesis, analysis and data extraction}

The lack of an existing holistic theoretical framework of how social networks influence the adoption of ORBs motivated the selection of lines-of argument synthesis (LOA) as the analysis strategy. It implicates building a general interpretation grounded in the findings of separate studies identified by constant comparison between individual accounts and grouped in themes that are most powerful in representing the entire dataset [42]. This consisted of coding inductively empirical data, specifically, sentences from the participants' quotes in the qualitative and mixed-methods papers and the text pertaining to the results, discussion and conclusions sections in the mixedmethods and quantitative studies (see Additional file 1). A key aspect of the analysis consisted on the synthesis and integration of the qualitative, mixed-method and quantitative data. According to the type of integration, this review is a data-based convergent synthesis design [69]. This means that all the included studies are analysed using a specific method, in this case, a qualitative synthesis method (CIS review). Since only one synthesis method is used for all the empirical evidence, data transformation is involved (quantitative data are transformed into qualitative data using categories/themes). Thus, quantitative, mixed-methods and qualitative results are presented together to answer the same objectives $[69,70]$. These codes from the text and quotes from the qualitative, mixedmethods and quantitative articles $(n=277)$ represent the first-order constructs. The next step consisted of grouping these codes in wider categories, turning these into descriptive themes [71]. These data-driven themes or secondorder constructs represent the original researcher's interpretations based on first-order constructs in order to describe the content of the empirical studies [72]. In this review, three data-driven themes were created. 


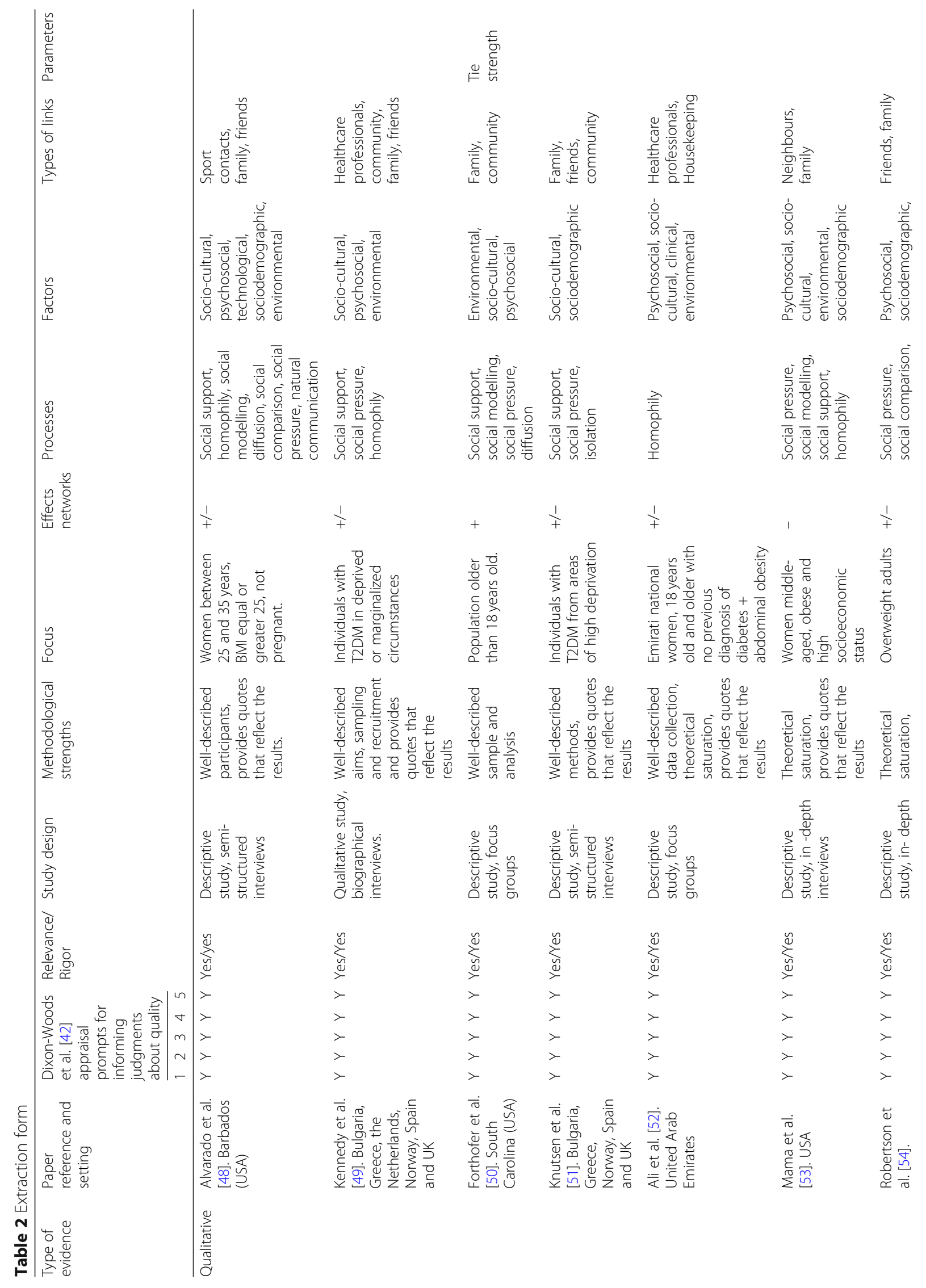




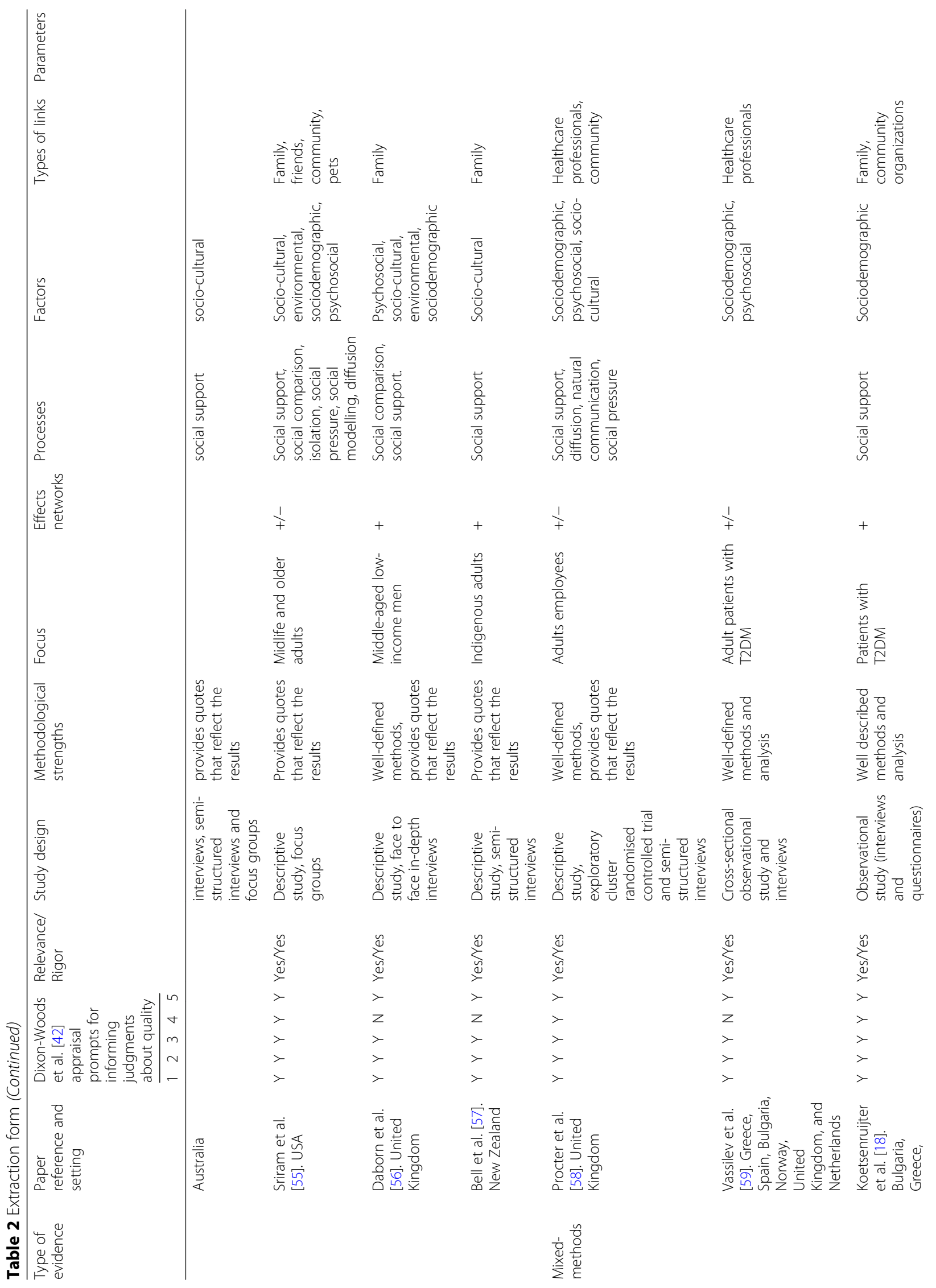




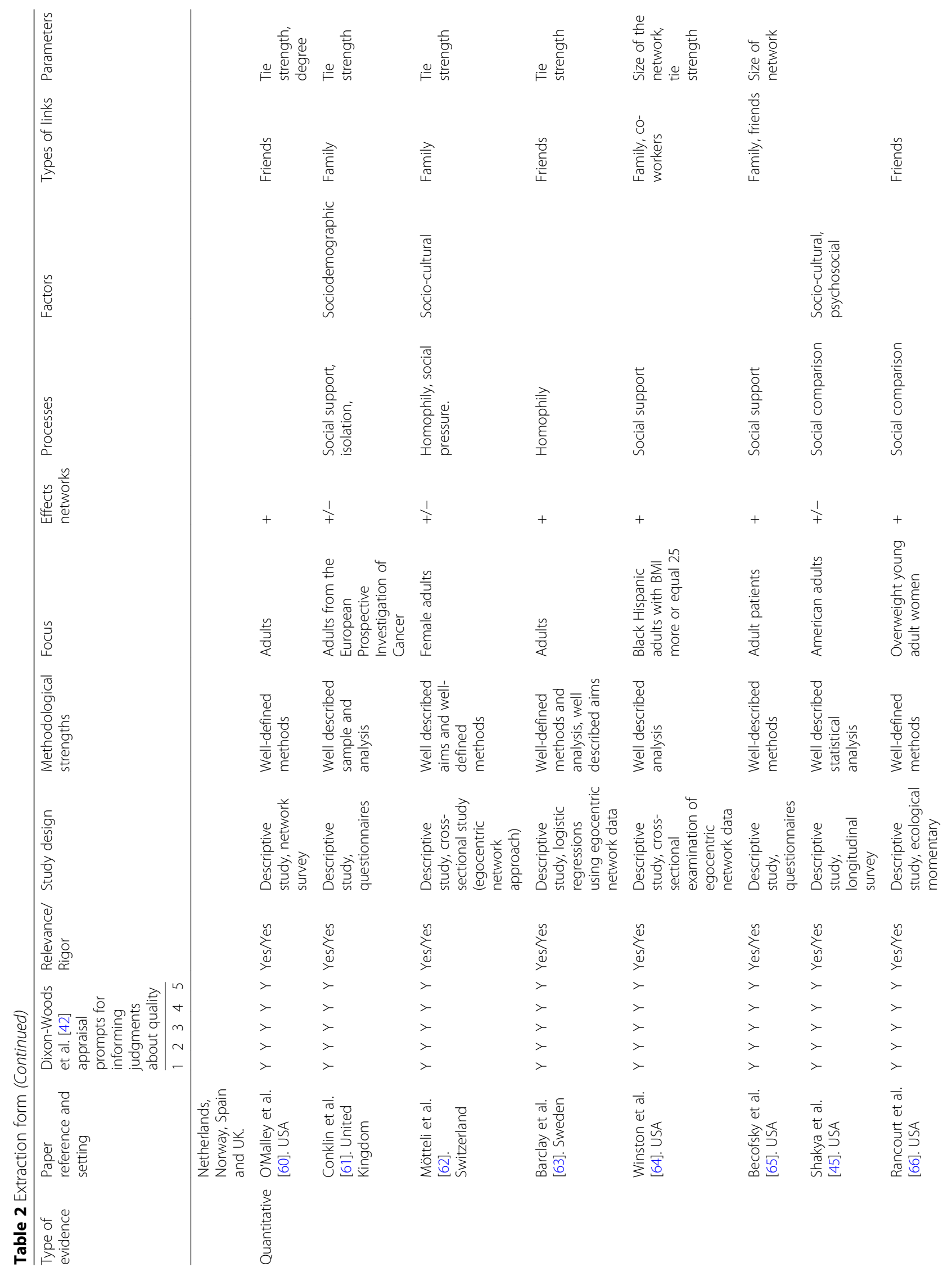




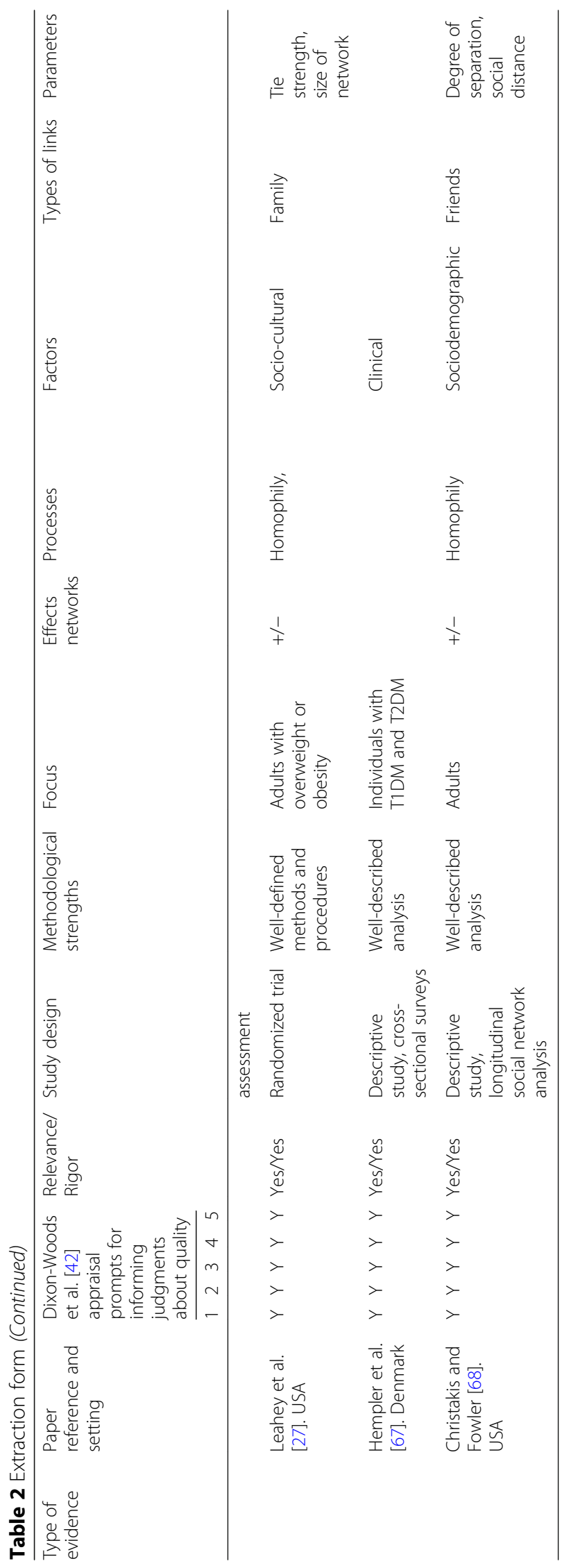


As it is shown in the 'results' section, the varied combinations and integration between these drivers can explain and modify the different results in health. The information was integrated from the studies into a coherent theoretical framework comprising a group of constructs and the relationships between them [42] producing a synthesizing argument of how social networks and the context influence the adoption of ORBs in adults. Consequently, theory-driven or third-order constructs were created built on the explanations and interpretations of the studies [42] to determine new implications for the understanding more in-depth how social networks influence the adoption of obesity and the development of future social networks interventions applied to ORBs in adults. The authors involved in the review discussed and confirmed the themes between them and other members of their research team as part of a process of reflexive dialogue against framing the analysis according to a single perspective.

\section{Results}

After all data searches were completed 28,289 citations were retrieved, of which 12,908 were duplicates. A further 15,198 records were excluded based on title and abstract. After applying the inclusion/exclusion criteria, 183 papers were identified for full screening. After 39 articles were excluded as irrelevant to the aim of the CIS, 144 papers were identified for eligibility (127 from database searching, 15 from manual searching and 2 from snowballing). Of the 144 studies screened, 106 were excluded after a full paper screening and 14 after theoretical saturation [73]. Through the theoretical sampling, qualitative $(n=10)$, mixed-methods $(n=3)$ and quantitative studies $(n=11)$ were included and reviewed until theoretical saturation was achieved [47, 73-77] (see Fig. 1). Theoretical saturation is the point at which additional data does not lead to any emergent themes or concepts in the analysis [78-80]. It was relevant here as broad spectrum criteria for the inclusion and exclusion of identified relevant articles. In this review, theoretical saturation signalled the end of the identification of articles in which social relationships were related to the adoption of ORBs in adults. It needs to be highlighted that although grey literature was also reviewed, it was not included in the final analysis of review findings since it did not provide sufficient relevant information on the topic. Thus, 24 articles were theoretically rich enough and of central relevance to the aim.

\section{Data-driven themes}

Three data-driven themes were developed from the reviewed literature: meso-micro network processes for the adoption of ORBs, contextual and individual factors of ORBs, and types of ties and properties that influence the adoption of ORBs.
The abstraction of the inductive concepts covered two levels of analysis. The following levels of analysis with their initial characteristics are adapted for this article based on relevant research of other authors [35, 75, 81-85]:

- Meso-level: describing relationships with healthcare professionals and other individuals from the community or locality (neighbourhood, suburb, city).

- Micro-level: examining a person's closest social circle-peers (family, friends, co-workers, pets) and individual characteristics (biological, psychological and personal history factors).

\section{Meso-micro network processes for the adoption of obesity- related behaviours}

Network processes are responsible for tie formation and outcomes [86] located within a social context that shapes practices, behaviours and the roles and functions that networked individuals achieve [49]. These network processes are classified into the different levels of analysis according to the nature of and involvement of ties participating in the relationships.

The reviewed papers identified network processes at the meso and micro levels of analysis. Regarding the meso-level, the most relevant processes were social support $[48,49,51,55,58]$ (Table 3, Q1 and Q2) and social pressure $[48,50,51,55,58]$ found in 5 articles which have both positive (Table $3, \mathrm{Q} 3$ ) and negative effects on health. For example, in terms of positive effects, a conversation in the streets with a friend from the gym might exert positive social pressure and increase the motivation to exercise [48]. With regard to negative effects, individuals with specific cultural norms might for instance influence the quality and amount of food intake (Table 3, Q4). Another relevant network process is homophily $[48,49,52,68]$, the tendency of pairs of individuals to share the same characteristics [20], described as a positive network process to exercise -e.g. when individuals share the same gender (T1 in Table 3). The diffusion of new health information is also linked to positive effects on the adoption of ORBs (see Q6 in Table 3).

The micro-level is represented more than the meso-levelmentioned in 21 articles [18, 27, 45, 48-58, 61, 62, 64-66, 68] with 13 articles identifying social support as an essential network process for the adoption of healthy practices $[18,48-51,53-57,64,65]$. As social support is a broad concept, it was sub-divided. Peer support by family members was key to acquiring good dietary habits [56] (Table 3, Q8) and group support to performing physical activity [49], as of Q9 in Table 3. Homophily [62] (Table 3, T6) and social comparison [45] with families and friends also representing positive processes for the adoption of healthy ORBs in 


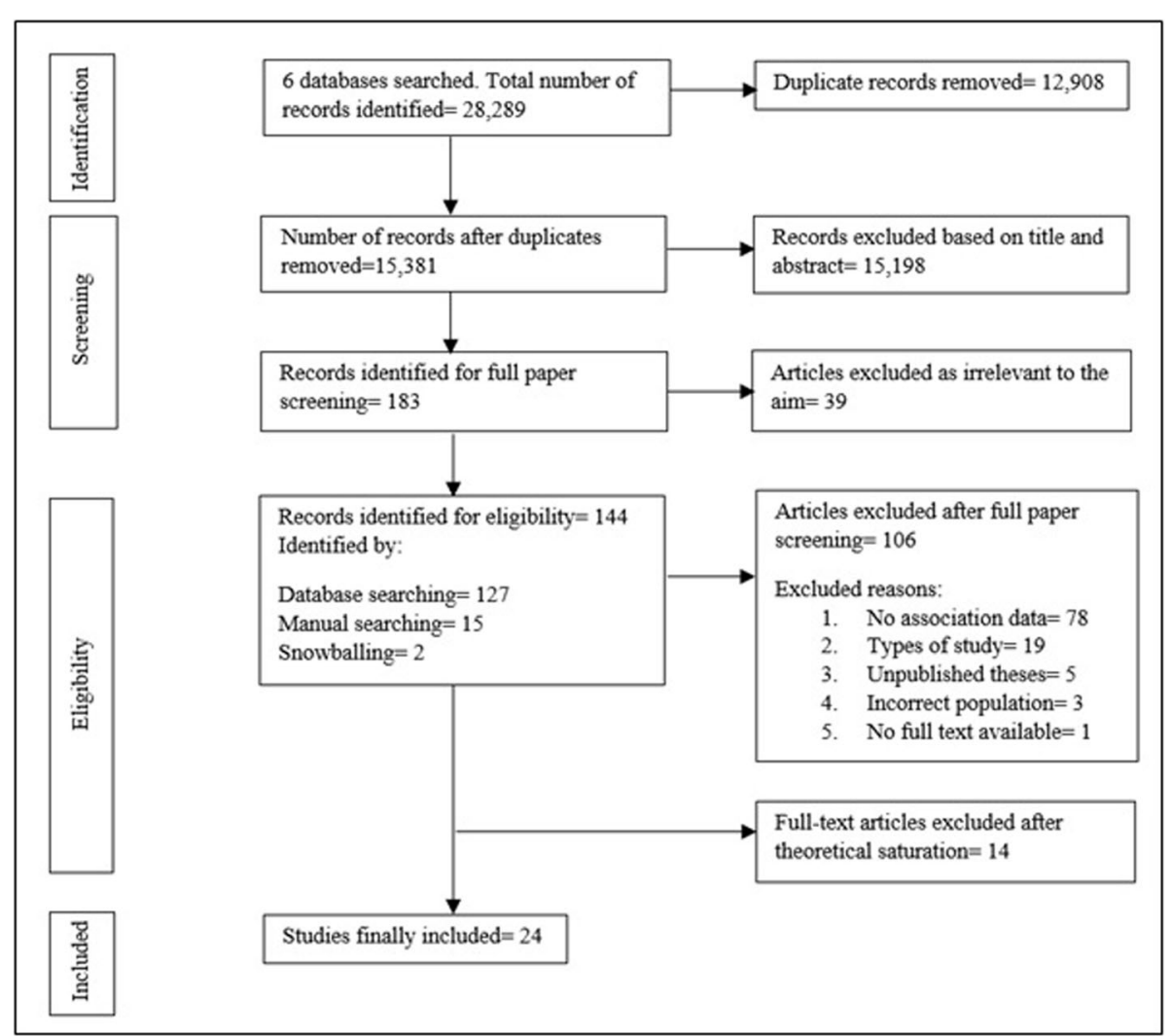

Fig. 1 PRISMA flow of studies included in the review

adults. For instance, as shown in T4 in Table 3, individuals might make decisions about their own health whilst they are comparing their body size with others. The presence of negative effects on health included isolation, described as a high-risk factor of developing unhealthy behaviours $[51,55,61]$ and a variety of diet (Table 3, T7). The network facet of social pressure showed dual effects $[49,51,53,54,62]$. For example, a negative effect is when friends push the individual not to follow the diet in the context of a social event (Table 3, Q7 and T5). A positive effect is the pressure that the family exerts on the individual's diet (Table 3, Q7) or when a friend encourages the individual to exercise [53]. Finally, natural communication [48, 58] and social modelling [50, 53, 55] were described in the reviewed literature in both levels of analysis as processes for the adoption of positive ORBs, as illustrated in T2, Q5, T3 and Q10 in Table 3.

\section{Contextual and individual factors for the adoption of obesity-related behaviours}

In addition to meso-micro network processes, there is evidence that shows how other contextual and individual factors influence the adoption of ORBs in adults.
With regard to the meso-level, environmental factors described in 7 articles $[48-50,52,53,55,56]$ the lack of conducive built environments were considered to be the main barriers to exercise (Table 3, Q11), whilst community resources such as group activities stimulate the adoption of healthy activities in older people (Table 3, Q12). Additionally, socio-cultural factors [48, 49, 51, 52, 55, 57] were considered a positive and negative influence on normative social responses to individuals' behaviours. For example, regarding negative effects, gendered norms are included in some communities which may impact through presenting a barrier to be overcome in order to perform physical activity (Table 3, Q14).

Eighteen articles described contextual and individual factors at the micro-level $[18,27,45,48-56,59,62,63$, $67,68,87]$ and 11 articles showed that psychosocial factors $[45,48-50,52-56,58,59]$ play an essential role in the adoption of ORBs. For example, regarding positive effects, living through critical moments like the loss of a relative [56], possessing high internal motivation [53], self-efficacy [54] and a specific knowledge about healthy food [52] are facilitators to change health behaviours, as stated in Q16, Q17, Q18 and Q19 in Table 3. Nevertheless, personal attitude is sometimes a barrier; this is the case when a person decides between the use of the car 
Table 3 Data-Driven Themes abstracted from quotes and text of the articles

Data-Driven Themes Quotes and Text From Findings

Meso-micro network processes

Q1(+). "Several participants suggested external health promoters could provide additional encouragement:

'Somebody coming in from outside, say doing half an hour at lunchtime just doing a presentation about it or, you know, longer and getting people there and talking about that and saying 'and we have our in-house person who you know if you want to talk to him, d'you wanna get encouragement from him/her' that would be great but I think somebody coming in from outside actually would be a good idea." [58] Q2(+). "That's why I think the group would be kind of cool to get together with... to get together as a group and just share some ideas ..." [55]

$\mathrm{T} 1(+)$. "During follow-up visits all but one woman in the study agreed that men and women were not active together. In contrast, women reported discussing exercise with other women and joining all-female exercise groups." [48]

Q3(+). "I probably would pass somebody from my gym somewhere on the streets [... It's] motivational in the sense that if you don't go [...to the gym] and pass a girl that I haven't seen in a while 'hey why I don't see you in the gym? What's going on with you?' and I guess guilt people into coming back. So yeah it's motivation." [48]

Q4(-). "However, if I go back to the village where my husband comes from, they are country people and they love to bake, cook and it's lovely. It's gorgeous and because they know you're coming for afternoon tea, they'll have made you the apple pie and they'll have made you the cakes and if you went in there and tried to start explaining that you don't eat any of that... In that sort of culture, it just would not be understood, and also you're interfering with the social norms and you don't want to do that." [51] T2(+). "WhatsApp groups comprised of women in the same exercise class could make this social pressure and social support even stronger." [48]

Q5(+). "We have people in my neighbourhood that you can be leaving out at five in the morning, and they're walking. You can come in at six in the afternoon and there's another group walking...We have a monthly HOA [homeowners association] meeting - and sometimes in those meetings people just go, "Hey, I saw you walking. Can I join your group?" [53]

Q6(+). "Overall the promoters found their booklet 'was well set out' and helped them approach participants: 'It was informative and useful and helped me set out what I needed to do, promote walking to work to the colleagues, and how to approach them and stuff, I thought it was quite good." [58]

T3(+). "In contrast, having tight social networks was viewed as beneficial if friends were "health-conscious" and acted as positive role models." [55]

T4(+). "In the case of body size, a descriptive norms effect can work through direct comparison so that a person compares himself to others in his social reference group and makes decisions regarding his own status according to that metric." [45]

Q7(+). "My husband insists that I shouldn't eat large quantities or any starchy food. My mum always scolds me, but this doesn't help; she just gets on my nerves. As soon as she sees me eating even the smallest amount of sweets, she'll start complaining. I can't say my daughters are indifferent. They'll remark when I overeat something. Everyone is focused on my diet." [51]

T5(-). "Social events involving food were areas where maintaining normal social ties were often more important than attempting to force attention on dietary needs." [49]

Q8(+). "I used to eat a lot of vegetables when I was at home, cause my wife was an extremely good cook, so we ate really well, I don't mean gluttony I mean just healthy food." [56]

Q9(+). "We are trying to exercise together, all of us... We aim to create a large group and include family and kids and socialize very often, so it becomes a big group and better habits." [49]

T6(+). "More precisely, women and their most important eating companions tended to be similar in dietrelated factors such as diet quality and eating styles as well as in BMI." [62]

Q10(+). "...found myself you know doing the walking home without having written it down and you know having told several people - I mean telling people that that's what you're doing actually makes you hold to it even more than if you, if I'd written it down." [58]

T7(-). "Several elderly women also discussed the negative consequences of living alone on their diets. Without family members around, eating decisions were primarily based on convenience and several participants reported having no incentive to make dietary improvements at their advanced age." [55]

Contextual and individual factors
Q11(-). "Close to my house, there are no sidewalks. And I feel like I don't want to get in the car and drive somewhere and get out and walk and get back in the car... I used to walk a lot, but I lived somewhere else so it made it very simple." [50]

Q12(+). "I'm looking for more, all the time... I'm getting ideas at the moment because when I go to the sports centre they've got loads of activities for older people like me and other illnesses, not just diabetes, they cover everything there." [49]

Q13(-). "When the weather is cold I walk, but it is difficult to walk in summer." [52]

T8(+). "Participants described food-centric social events as a primary constraint to eating well. Limited entertainment options in these rural communities meant that most activities involved getting together for a snack or meal. Food provision was regarded as a sign of "hospitality" and people felt obligated to eat whatever was offered in social settings (e.g., church, senior centers)." [55]

Q14(-). "Walking is not culturally acceptable. My husband will not allow me to walk in the street but if it is a closed place [gym] he has no problem." [52]

Q15(+). "Going to the gym the motivation is, well obviously it would be generally to lose weight, but going by the gym is relatively small so you know everybody that is there so it's kind of a family type atmosphere." [48] Q16(+). "My grandmother... when I was $13 \ldots$ I was the sole witness to her coronary occlusion which killed 
Table 3 Data-Driven Themes abstracted from quotes and text of the articles (Continued)

Data-Driven Themes Quotes and Text From Findings

her on the spot and I never quite dealt with that so it has left me with a bit of a fear of heart disease and heart problems and seeing how violently they can end your life." [56]

Q17(+). "There is some type of apprehension in the back of my mind, and I'm trying to figure out why, but I really need to say, "Go ahead, start doing it." I guess I feel that if I start, I'm going to have to continue. It's going to change my routine. [And that] Moves me out of my comfort zone." [53]

Q18(-). "I have the control to change things I just don't change them, and I don't know why. It's ridiculous." [54]

Q19(-). "The food we eat is not healthy because of the way we cook it and because we do not know enough about healthy food." [52]

Q20(-). "I think people [study participants] have the intentions of walking ... but, because their character is, just they don't know how to live without the car." [58]

T9(-). "During treatment, participants lost an average of $4.4 \%$ of initial body weight, and social influence factors were adversely associated with weight loss outcomes. Having more casual friends who were overweight at baseline and being part of a social network with stronger social norms for unhealthy eating predicted poorer weight losses (p's <.023)." [27]

Q21(-). "I look after my husband, the house, everything. I don't look after myself as much as I used to. In the past, I would cook something for myself and something for the others to eat... I have to cook meals that my children and grandchildren like because my daughter works, and so I eat from these as well, so I don't miss out." [51]

T10(-). "This man emphasizes the need to occasionally not adhere to the diet, especially at parties and when with friends." [51]

Q22(-). "Without the help of my children, I wouldn't be able to cope. My pension is 140 leva - [not enough] for following a diet and buying drugs." [51]

Q23(-). "I worked as [...] a cashier at a supermarket until 2009 and you know a cashier sits down ain't much activity in that and then in 2009 to 2011 I did secretarial work - so that's even worse but then [...] I got this new job that I totally love cause since I really can't get the exercise that I want to put in..." [48] T11(+). "Specifically, people who reported good self-management skills were more likely to have a diverse network, to be older, to be in relatively good health, to have high levels of income and education, and to live in the wealthier of the six countries (Norway, UK, Netherlands, Spain). High levels of self-monitoring were also associated with high education and relatively good health." [59]

T12(+). "In these small rural towns, social interaction appeared to be an important facilitator of active lifestyles, particularly for women. Organized group activities, such as walking, were viewed as an opportunity to socialize with friends and connect with the community. Building these networks increased enjoyment and gave people more incentive to engage in activity." [55]

Q24(-). "Sometimes the walk is be good you know exercise but if I have my car I wouldn't walk at all only when I don't have do I walk cause everything closer in town [Bridgetown] that ya could walk to instead of wasting the gas but as for out here [St. Philip]... the closest shop there ... nah... now that is daytime no way! Ain't walking. Too hot!" [48]

T11(+). "Specifically, people who reported good self-management skills were more likely to have a diverse network, to be older, to be in relatively good health, to have high levels of income and education, and to live in the wealthier of the six countries (Norway, UK, Netherlands, Spain). High levels of self-monitoring were also associated with high education and relatively good health." [67]

T13(-). "People with type 2 diabetes were less physically active, less likely to follow recommended diet (men), had fewer contacts with family and friends and were less certain of counting on help in case of severe illness than people with type 1 diabetes." [67]

Types of ties

Q3(+). "I probably would pass somebody from my gym somewhere on the streets [... It's] motivational in the sense that if you don't go [...to the gym] and pass a girl that I haven't seen in a while 'hey why I don't see you in the gym? What's going on with you?' and I guess guilt people into coming back. So yeah it's motivation." [48]

T14(+). "In Bulgaria compared to elsewhere, health professionals' advice was taken more seriously and sought more frequently." [49]

Q4(+). "We have people in my neighbourhood that you can be leaving out at five in the morning, and they're walking. You can come in at six in the afternoon and there's another group walking... We have a monthly HOA [homeowners association] meeting — and sometimes in those meetings people just go, "Hey, I saw you walking. Can I join your group?" [53]

T15(+). "Attending community organizations was positively related to physical activity, however only for patients with a low income (OR=1.53)." [18]

Q25(+). “...my health...[is] my family...My children and husband, and our whanau whanui (tribal family) ... our wellbeing is whanau (family)... [when] someone else is not well in our family, that has an impact...on our health...I'm connected to those people and our children... the heavier we are collectively, the better off we are individually..." [57]

Q26(-). “No, my family doesn't help me. I am responsible for health issues at home... I ask them to support me a bit more, taking the cakes out of my sight, but they're all tomboy-like and take little care of me. They don't see a disease in my diabetes." [49]

T16(+). "Whether the target was a friend moderated these effects. When engaging in an upward comparison to a friend, participants had more thoughts of exercising compared to when the target of the upward comparison was not a friend $(Y=1.03, P=0.031)$. When engaging in a downward comparison to a 
Table 3 Data-Driven Themes abstracted from quotes and text of the articles (Continued)

\begin{tabular}{ll}
\hline Data-Driven Themes & Quotes and Text From Findings \\
\hline & friend, participants also reported more thoughts of dieting $(Y=2.68, P=0.006)$ and exercising $(Y=2.13, P=$ \\
& 0.024) as compared to when targets were nonfriends." [66] \\
T9(-). "During treatment, participants lost an average of $4.4 \%$ of initial body weight, and social influence \\
factors were adversely associated with weight loss outcomes. Having more casual friends who were \\
overweight at baseline and being part of a social network with stronger social norms for unhealthy eating \\
predicted poorer weight losses ( $p$ 's $<.023)$. ." [27] \\
Q27(-). "Our weights increase because we have housemaids and we depend on them a lot." [52] \\
T17(t). "In a multivariable regression model, greater weight loss was associated with help from a child with \\
eating goals ( $p=.0002)$ and co-worker help with physical activity $(p=.01) . "$ [64] \\
T18(+). "For several participants, pets provided much needed companionship and reason to be active. Pets \\
appeared to be especially important motivators of physical activity for elderly individuals living alone." [55]
\end{tabular}

Properties of social networks

T19. "Lower frequencies of family contact were associated with lower fruit variety scores and rare/no contact was similarly negative for both genders. By contrast, decreasing family contact seemed to have limited association with vegetable variety in men whereas weekly contact had a 0.56 unit difference $\left(p \frac{11 / 4}{0.001)}\right.$ in score in women compared with daily family contact." [61]

T20. "The degree to which this behaviour is shared is modulated by the strength of the relationship between the two individuals, with a greater probability of engaging in these behaviours observed when the relationship with the nominated peer is strong relative to when the relationship is weak." [63] T21. "Moreover, having more friends is associated with an improvement in health, while being healthy and prosocial is associated with closer relationships. Specifically, a unit increase in health is associated with an expected 0.45 percentage-point increase in average closeness, while adding a prosocial activity is associated with a 0.46 percentage-point increase in the closeness of one's relationships." [60]

T22. "Participants reporting social contact with 6 or 7 friends on a weekly basis had a 24\% lower mortality risk than those in contact with $\leq 1$ friend (HR $0.76,95 \% \mathrm{Cl} 0.58-0.98)$." [65]

T9. "During treatment, participants lost an average of $4.4 \%$ of initial body weight, and social influence factors were adversely associated with weight loss outcomes. Having more casual friends who were overweight at baseline and being part of a social network with stronger social norms for unhealthy eating predicted poorer weight losses (p's < .023)." [27]

T23. "Whereas increasing social distance appeared to decrease the effect of an alter on an ego, increasing geographic distance did not. The obesity of the most geographically distant alters correlated as strongly with an ego's obesity as did the obesity of the geographically closest alters. These results suggest that social distance plays a stronger role than geographic distance in the spread of behaviours or norms associated with obesity." [68]

or walking to commute (Table 3, Q20). Moreover, sociocultural factors were described in 13 articles [27, 45, 48$56,58,62]$, showing negative effects on health in most of the examples. This is the case concerning social norms [27], social events [51] and competing demands [55] such as family responsibilities (caring, children hobbies). Sociodemographic factors were identified in 11 articles $[18,48,51,53-56,58,59,61,68]$ with socio-economic status $[18,48,51,54,56,59]$ and gender $[54-56,59,61,68]$ having positive and negative effects. A poor socio-economic status with a lack of social support might be a barrier to accessing healthier food in following a healthy diet (Table 3, Q22). On the other hand, having high levels of income is associated with better education and the self-report of good self-management skills (Table 3, T11). In terms of gender, women are seemingly more willing to participate in community groups and work with a shared aim collectively than men (Table 3, T12). Certain types of jobs, age, transport and education were also mentioned (Table 3, Q23, T11 and Q24). Clinical factors such as underlying medical conditions are barriers to performing physical activity [67]. For example, individuals with type 2 diabetes are more willing to exercise than individuals with type 1 diabetes (Table 3, T13). This may be because overweight and obesity, which in many cases, accompanies type 2 diabetes, might be the precipitating factor.

\section{Types of ties and properties of social networks for the adoption of obesity-related behaviours}

In this review, ties are understood as the links between individuals [20]. They are meaningful as different types of contacts offering potential ways to change behaviours.

Ten articles described weak ties at the meso-level. The strength of 'weak ties' hypothesizes that things flow from people with whom one has limited tenuous contact and relationality [87]. Here, community organizations and community groups $[18,49-51,55,58]$ were identified as relevant ties for the adoption of a good diet and physical behaviours. Also, networking with healthcare professionals and neighbours were identified as a means of getting involved with behaviour change, as illustrated in T14 and Q4 in Table 3. Twenty articles described contacts at the microlevel as key players for the adoption of ORBs. These included in the main strong ties, that is to say, relations between contacts that have strong bonding connections between them. In this regard, 15 articles related family contacts with positive and negative effects on health $[18,48-57$, 
$61,62,64,65]$. For example, there may be cases where family members might be supportive or not with diet (Table 3, Q25 and Q26). Friends were also mentioned in 11 articles as key players $[27,48,49,51,54,55,60,63,65,66,68]$. It is seemingly easier to engage in exercising if individuals compare themselves with friends [66] (Table 3, T16). On the other hand, there is a high risk of adopting bad dietary habits if a person belongs to a group of friends with overweight and with a strong set of social norms for unhealthy eating, as stated in T9 in Table 3. Finally, according to the literature sports contacts [48], housekeeping [52], co-workers [64] or pets [55] are identified as types of ties at the mesomicro levels of analysis (Table 3, Q3, Q27, T17 and T18).

Networks are formed by individuals and the ties among them and thus, it is relevant to continue the description of networks by examining simple properties or measurements of these social structures [86]. Some key features of the social networks were essential to define the structure of the network and patterns of the adoption of ORBs in adults. More concretely, in 7 articles [27, 50, 60-64] the tie strength (frequency of contact and feeling of closeness) with members of the family or healthy companions consistently describes higher diet quality as it can be seen in T19 and T20 in Table 3. Another property to consider is the degree or number of contacts that each individual possesses. Having more friends is related to healthier habits (Table 3, T21). Moreover, the size of the network is relevant for positive and negative effects $[27,64,65]$. The bigger the network an individual is part of with poor health habits, the harder it might be to lose weight (Table 3, T22). By contrast, individuals reporting social contact with six or seven friends have more opportunities to engage in healthy behaviours than those in contact with only one friend (T9 in Table 3). Finally, distances between members of the network were considered in terms of social distance (degree of separation) and geographic distance. The social distance is the distance that an individual is from others [88] (e.g. the distance between two adjacent individuals is one). A study of the spread of obesity in a large social network over 32 years demonstrated that increasing social distances appeared to decrease the influence of contacts to enhance weight gain in the individual, but increasing geographic distance did not [68], that is to say, the geographical distance did not modify the effect of those contacts. Thus, social distance could play a stronger role than geographic distance in the spread of behaviours or norms associated with obesity.

\section{Theory-driven themes}

The aim of the review required an in-depth exploration of how data-driven themes influence the adoption of positive and negative ORB's in adults. Two theory-driven themes have been developed from the synthesizing argument to complete this theoretical framework, and the understanding of the events studied (see Fig. 2). These themes are developing multi-agent coalitions and crosslevel influence.

In the process of the review, different health scenarios where social networks are present in the adoption of ORBs have been broken down to different levels of analysis. In each scenario (text or quote), various components have been identified and coded individually, showing their positive and negative effects on health. They were then grouped in wider categories or data-driven themes. These themes were meso-micro network processes, contextual and individual factors and types of ties and properties of social networks. Nevertheless, during the process of analysis, it has been shown how the majority of the components cannot act on their own but were mediated in some way to affect health. Thus, developing multi-agent coalitions is a driver that highlights the necessity of the combination and influence between these different concepts, developing power of cumulative effects. These different multi-agents coalitions produce and, therefore, acknowledge both positive and negative health outcomes in the individuals. For example, social pressure by close contacts (friends or family) at micro-level has shown typically positive results in this review [51, 53, 54, 62]. Nevertheless, if a socio-cultural factor (e.g. social events) is considered, this effect might be more harmful. In this latest case, it is shown how a positive effect is reversed into a negative one by adding an extra component (contextual factor). The following two examples represent this fact.

\section{"My husband insists that I shouldn't eat large quantities or any starchy food. My mum always scolds me, but this doesn't help; she just gets on my nerves. As soon as she sees me eating even the smallest amount of sweets, she'll start complaining. I can't say my daughters are indifferent. They'll remark when I overeat something. Everyone is focused on my diet." [51]}

This example represents, a multi-agent coalition culminating in a positive effect on health: Family (type of tie, micro-level) + social pressure (process, micro-level).

"This man emphasizes the need to occasionally not adhere to the diet, especially at parties and when with friends." [51]

This last example, which was extracted from the same article as the previous one, shows how adding an extra data-driven theme (party, social event) changes the effect into one, which is more negative. This coalition would be friends (type of tie, micro-level) + social pressure (process, micro-level) +social events 


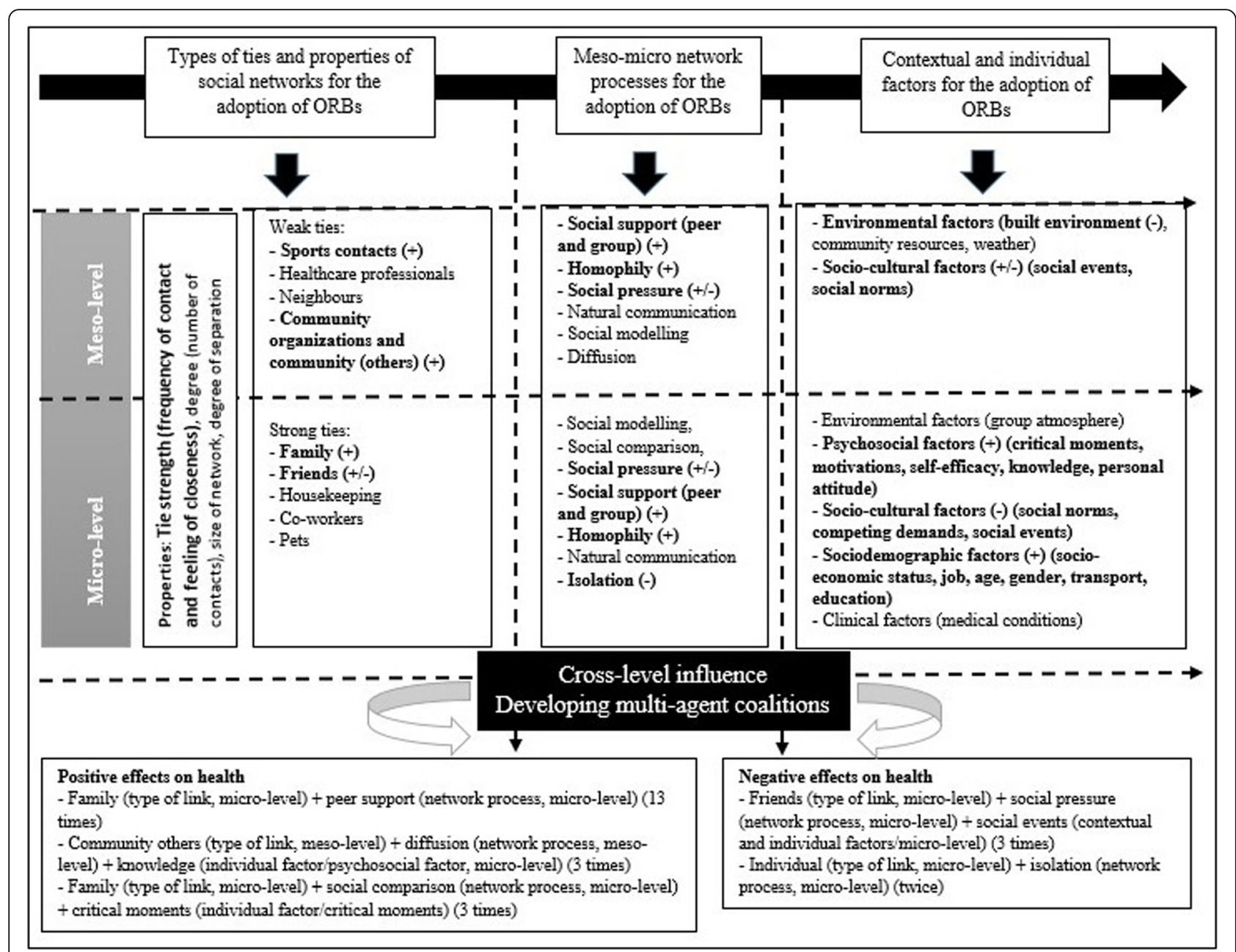

Fig. 2 Complex system approach with inductive constructs. (Legend) The most relevant constructs are highlighted in bold. (+) and (-) symbols explain if the constructs have positive or negative effects on health. The two theory-driven themes point to different coalitions with positive and negative effects on health

(contextual and individual factors/socio-cultural factors, micro-level).

The identified relevant combinations implicating positive and negative effects on health are available in Additional file 2. The most relevant multi-agent coalitions are presented below, based on the number of times that appeared in the chosen articles and classified into positive and negative health effects.

Positive effects:

- Family (type of link, micro-level) + peer support (network process, micro-level) (13 times).

- Community others (type of link, meso-level) + diffusion (network process, meso-level) + knowledge (individual factor/psychosocial factor, micro-level) (3 times).

- Family (type of link, micro-level) + social comparison (network process, micro-level) + critical moments (individual factor/critical moments) (3 times).
Negative effects:

- Friends (type of link, micro-level) + social pressure (network process, micro-level) + social events (contextual and individual factors/micro-level) (3 times).

- Individual (type of link, micro-level) + isolation (network process, micro-level) (twice).

Cross-level influence refers to the dynamic relationship between the individuals that are embedded in social relationships and the context at multiple levels of analysis, in this case, micro and meso levels. This concept cannot be understood without the influence of developing multiagent coalitions. Two examples with the involvement of different levels of analysis are illuminating:

"I probably would pass somebody from my gym somewhere on the streets [... It's] motivational in 
the sense that if you don't go [...to the gym] and pass a girl that I haven't seen in a while 'hey why I don't see you in the gym? What's going on with you?' and I guess guilt people into coming back. So yeah it's motivation." [48]

This event is formed by a type of link (sports contacts, meso-level), a network process (social pressure, mesolevel) and an individual factor (psychosocial factor/motivation, micro-level).

"Participation and attendance at the pub involve negotiations and a counterbalance of the intake of beer and the health promoting effects of positive social relationships taking place at the pub." [51]

This coalition can be interpreted as the combination of friends (type of tie, micro-level) + peer support or group support (process, meso-level) + social norms and social events (contextual factor/socio-cultural factor, meso-level).

Thus, as per Fig. 2, it can be seen that developing multi-agent coalitions and the presence of cross-level influence between the different data-driven themes produce positive and negative ORBs.

\section{Discussion}

This CIS offers an opportunity to gain novel insights regarding how social networks influence the adoption (or abandonment) of positive and negative ORBs in adults with obesity, overweight or risk of obesity. The qualitative, quantitative and mixed-method empirical evidence from the reviewed papers were included in the process of the development of new themes and a synthesizing argument with the aim of addressing a gap found in the literature namely what and how network properties and processes together with other environmental factors produce positive and negative health outcomes in adults with ORBs.

The consideration of all dimensions of network analysis and exploration, that is to say, structure, function, strength and content required the contribution of both qualitative and quantitative approaches. Traditionally, theories have identified a variety of processes in social networks and obesity research, generating discussions between researchers about aspects of social selection, social contagion, confounding, social influence [32, 68, 89, 90]. Here our focus is mainly on social influences, which have been classified under the umbrella term of social processes in order to open up new ways of discussion about the underlying processes of social networks.

A strength of this article was the application of social network theory which in previous studies identified the importance of relationships in the adoption of ORBs but without considering this network approach $[48,52-57,61,62]$ in a manner which illuminates the depth, meaning and structure of these relationships and associations with contextual and environmental factors. This affirms that structural and functional characteristics of social networks together with environmental and personal factors may contribute to health behaviours [91-93]. Several authors have recognized some of these ideas before, but individually and in the absence of considering the sum of other factors in the adoption of health behaviours [37-39, 94, 95]. This review presents an integrated developed contribution in comparison with the previous studies, in particular flagging up how the combination and the relationship between these concepts at different levels of analysis produce positive, negative and contingent health behavioural outcomes in adults with ORBs. Thus, different agents were identified at two levels of analysis (meso and micro levels). This research resonates with Bronfenbrenner's ecological theory [35] since it was concerned with tackling numerous environmental factors and numerous persons in different interaction relationships, roles, actions and processes. Nevertheless, the formula of using the six different levels of analysis (individual, microsystem, mesosystem, exosystem, macrosystem and chronosystem) do not equate with our idea about open system thinking, which is more related with the multilevel approach of social network theory. Thus, the levels of analysis are simplified into, micro, meso and macro levels $[81,96]$. In this regard, networks are understood as a dynamic response to individual interactions [97]. It implies that social interaction is actually the most elementary unit of social belonging and dynamics, and thus that it is what generates social spaces and positions $[98,99]$. Following this, we cannot consider in the same level of analysis (e.g. micro-level), for example, the role of family and health services, since the interaction of the individual with them might be potentially different. Similarly, in the micro-level we have identified the potential contacts that have a stronger and closer relationship with the individual. In the meso-level, community contacts and less-frequent contacts are situated. This way of thinking is in line with other authors' research [62, 63]. Also, we have decided to propose the meso-level as the limit of the analysis because of the relevant amount of available.

The main focus of this CIS is to show how networks, together with the environment, influence the adoption of ORBs. During the process of analysis of data, different health scenarios were broken down into different themes at different stages. This process allows the creation of a 'story' (synthesizing argument) that explores 'what' and 'how' these new themes influence the adoption of ORBs. As a consequence, two new synthetic constructs developing multi-agent coalitions and cross-level influence point to a dynamic multilevel set of influences between multiple constructs (data-driven themes) that produce different positive and negative health results. With regard 
to positive effects, the combination of family (type of link, micro-level) with peer support (network process, micro-level) is the most important because it was the most mentioned in the literature (thirteen times), showing the engagement of individuals in health behaviours. By contrast, with regard to negative effects, the combination of friends (type of link, micro-level), with social pressure (network process, micro-level) and social events (contextual and individual factors, micro-level) is the most relevant (appearing three times). In relation to this, a relevant aspect that has been uncovered during the review is the potential power that the data-driven themes possess to address or reverse unwanted effects in which context plays a significant role. For example, social pressure by family at micro-level has typically positive effects on health. This is the case when the family control what an individual is eating at home. Nevertheless, social pressure exerted by close contacts in concrete social events (e.g. parties, pubs) enhances the adoption of negative ORBs, such as the intake of unhealthy food.

These results could have utility for health policy, considering the design of innovative interventions based on the integration of social networks and other contextual factors at multiple levels of analysis. The development of multi-agents coalitions between the different individual components of the data-driven themes created, using cross-level influences might be suitable to apply in the complex environment where individuals live. Thus, per example, this review has shown that the coalition family (type of link, micro-level) with peer support (network process, micro-level) has potential positive influences on health. In this sense, it would be interesting to explore the design of interventions where different members of the family could be embedded. For example, delivering educational programmes to the family rather than the individual or the collective participation of the family in different community assets and activities. This might enhance the influence of other members in the community and the exertion of group support (e.g. running group). In these examples, different aspects of networks together with contextual factors are present. The use of social network online tools based on social prescription and acknowledgement of new resources instead of the typical and well-known resources of the community to support this engagement with self-directed support might be relevant. Social network online tools might be used to identify other members of an individual network (apart from the family) that might be interested in sharing these activities with other people, even to connect isolated' individuals to others and these community assets or activities. This would potentially increase the size of the social network to avoid isolation and loneliness in adults, both risk factors for mortality associated with obesity. Isolation has been identified in this review as one of the main issues in ORBs. The most relevant scenario of negative health effects in this CIS was the combination of friends (type of link, micro-level), with social pressure (network process, micro-level) and social events (contextual and individual factors, micro-level). In this sense, it has been demonstrated in the results section how different constructs such as the contextual factor 'social event' has the power to reverse positive health effects. From a health policy perspective, it might be relevant to modify contextual and individual factors such as paying greater attention to how we can create or modify infrastructures and environments to practise physical activity or enhance the self-efficacy of avoiding unhealthy practices (e.g. alcohol intake, high-sugar food) in social events. The consideration of attending specific social events (e.g. regular meetings in pubs), in which the relationships influence negatively, might be relevant for predicting potential negative results. The regulation and limitation of alcohol intake or an increase in its price in local and macro festivals and pubs (places where social relationships enhance their consumption) can be other actions. Additionally, the identification and visibility of influential individuals (e.g. friends that go to the gym regularly or celebrities that promote healthy cooking in the media) might be considered as a prominent mediator in engaging people who wish to make changes to their health behaviours and their social norms.

Consideration needs to be given to the nature of qualitative research and the understanding of the open social systems analysed in this review, suggesting typicality rather than the generalization of the data abstracted [100]. These results might not be reproducible and predictive against the different criteria used in quantitative research. The creation of the synthesizing argument with the results obtained in this review provides a novel and more conceptually deep starting point for future interventions, considering conceptualizations at multiple levels for theoretical and application-relevant interventions which quantitative studies alone are unable to provide. In order to explore the veracity content and nature of the ties and the specific contexts where these relationships occur, it is necessary to translate and use these finding in the design of interventions.

This CIS has limitations. Firstly, the findings contained in the included studies were interpreted according to our research interests. The lack of studies regarding how mechanisms and properties of social networks influence the adoption of health behaviours, in general, opens an easily questionable route of interpretation. In this sense, the transformation of quantitative data into a qualitative form followed a 'coding' process. The use of this analysis strategy to deal with quantitative data could be questionable due to the lack of reviews that integrate qualitative and quantitative data with which to compare. Another 
limitation is the restriction on searching only in the English and Spanish language. It may have excluded relevant articles. However, the requirement of translation could result in the misinterpretation of specific information. We are conscious that the final number of articles that explicitly identified the specific focus of social networks and obesityrelated behaviours were limited in number. Nevertheless, these were sufficient to attain theoretical saturation [47, 73-77]. In this sense, concepts and linkages between them were well-developed, and no additional data were needed. Finally, the authors are aware of how broad and complex the topic is. Although the aim is to provide a whole and innovative vision of an event, certain factors might require more in-depth analysis using other strategies and more empirical work.

\section{Conclusions}

This CIS offers a new way to understand the use of social networks in the 'obesity' field in open settings. Breaking down different health scenarios in an analytical process allows the creation of a synthesizing argument that explores 'what' and 'how' social networks together with environmental-difference effects influence the adoption of positive and negative ORBs in adults using a multilevel approach. The data-driven themes meso-micro network processes, contextual and individual factors, and types of ties and properties were identified individually as components and causes of different health scenarios. Nevertheless, these drivers do not act on their own. As a consequence, developing multi-agent coalitions considering cross-level influences between the data-driven themes are two mechanisms that were created to understand more in-depth how social networks and the environment influence the adoption of ORBs. These two new constructs point to a dynamic multilevel set of influences between multiple constructs (data-driven themes), developing scenarios where positive and negative health results are identified. This synthesizing argument could be considered by those designing future interventions and policy in this area, who might need to consider the wider open system of socially connected individuals and harness these forces to design new interventions where social networks and other contextual and individual factors operate together in a complex multilevel environment.

\section{Additional files}

Additional file 1: All data-driven. (DOCX $66 \mathrm{~kb}$ )

Additional file 2: Coalitions. (DOCX $33 \mathrm{~kb}$ )

\section{Abbreviations}

CIS: Critical interpretative synthesis; LOA: Lines-of argument synthesis; LTCs: Long-term conditions; NHS: National Health System; ORBs: Obesityrelated behaviours; UK: United Kingdom; USA: United States of America

\section{Acknowledgements}

Our thanks go to the National Institute for Health Research Collaboration for Leadership in Applied Health Research and Care Wessex (NIHR CLAHRC Wessex) for the funding to carry out this research.

\section{Authors' contributions}

NSF identified the need to review this area of research. All authors made a substantial contribution to the design of the study. NSF undertook the review and drafted the paper. AR and MCP revised all versions of the manuscript for important intellectual content and approved the final version. All authors agree to be accountable for the accuracy and integrity of the work.

\section{Funding}

This research was funded by the National Institute for Health Research Collaboration for Leadership in Applied Health Research and Care Wessex (NIHR CLAHRC Wessex).

Availability of data and materials

All data generated or analysed during this study are included in this published article [and its supplementary information files].

Ethics approval and consent to participate

Not applicable.

Consent for publication

Not applicable.

\section{Competing interests}

The authors declare that they have no competing interests.

Received: 26 March 2019 Accepted: 11 August 2019

Published online: 28 August 2019

\section{References}

1. World Health Organization. 10 facts on obesity. 2017. http://www.who.int/ features/factfiles/obesity/en/. Accessed 2 Jan 2017.

2. Wang YC, MCPherson K, Marsh T, Gortmaker SL, Brown M. Health and economic burden of the projected obesity trends in the USA and the UK. Lancet. 2011;378:815-25.

3. Ng M, Fleming T, Robinson M, Thomson B, Graetz N, Margono C, et al. Global, regional, and national prevalence of overweight and obesity in children and adults during 1980-2013: a systematic analysis for the global burden of disease study 2013. Lancet. 2014:384(9945):766-81.

4. World Health Organization. Obesity and overweight. Media centre. 2018. http://www.who.int/mediacentre/factsheets/fs311/en/. Accessed 5 Jan 2017.

5. Organisation for Economic Co-operation and Development. Obesity update 2017. 2017. http://www.oecd.org/health/health-systems/Obesity-Update-201 7.pdf. Accessed 5 Jan 2017.

6. Health and Social Care Information Centre, Lifestyles Statistics. Statistics on Obesity, Physical Activity and Diet: England. England: NHS; 2013.

7. Government Office for Science. Tackling obesities: future choices - project report. 2nd ed. London: Government Office for Science; 2007.

8. Nightingale G. Social determinants of health and health inequalities: focus on nutrition. Department of Health: England; 2015.

9. Department of Health. Adult obesity: applying all our health. 2018. https://www.gov.uk/government/publications/adult-obesity-applying-allour-health/adult-obesity-applying-all-our-health. Accessed 1 Jun 2019.

10. National Health System [NHS]. Obesity-causes. 2019. https://www.nhs.uk/ conditions/obesity/causes/. Accessed 3 Jun 2019.

11. National Institute for Health and Care Excellence [NICE]. Lifestyle changes for adults who are overweight or obese. London: NICE; 2019. https://pathways.nice.org.uk/pathways/obesity/lifestyle-changes-for-adultswho-are-overweight-or-obese. Accessed 3 Jun 2019.

12. Lemstra M, Bird $Y$, Nwankwo C, Rogers $M$, Moraros J. Weight loss intervention adherence and factors promoting adherence: a meta-analysis. Patient Prefer Adher. 2016;10:1547-59.

13. Jebb SA, Aveyard PN, Hawkes C. The evolution of policy and actions to tackle obesity in England. Obes Rev. 2013;14(Suppl 2):42-59. 
14. Millar L, Kremer P, de Silva-Sanigorski A, McCabe MP, Mavoa H, Moodie M, et al Reduction in overweight and obesity from a 3-year community-based intervention in Australia: the "It's your move!" project. Obes Rev. 2011;12(2):20-8.

15. Rogers A, Vassilev I, Sanders C, Kirk S, Chew-Graham C, Kennedy A, et al. Social networks, work and network-based resources for the management of long-term conditions: a framework and study protocol for developing selfcare support. Implement Sci. 2011;6(1):56.

16. Pachucki MA, Jacques PF, Christakis NA. Social network concordance in food choice among spouses, friends, and siblings. Am J Public Health. 2011;101(11):2170-7.

17. Voorhees CC, Murray D, Welk G, Birnbaum A, Ribisi KM, Johnson CC, et al. The role of peer social network factors and physical activity in adolescent girls. Am J Health Behav. 2005;29:183-90.

18. Koetsenruijter J, van Lieshout J, Lionis C, Portillo MC, Vassilev I,

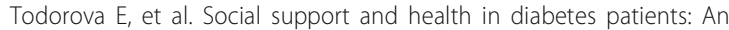
observational study in six European countries in an era of austerity. PLoS One. 2015;10(8):e0135079.

19. Brandes $U$, Robins G, Mccranie A, Wasserman W. What is network science? Network sciences. 2013;1:1-15.

20. Kadushin C. Understanding social networks. New York: Oxford University Press; 2012.

21. Perry BL, Pescosolido BA, Borgatti SP. Egocentric network analysis: foundations, methods, and models. Cambridge: Cambridge University Press; 2018.

22. Marsden PV, Campbell KE. Measuring tie strength. Social forces. 1984;63(2): 482-501.

23. Emirbayer M, Goodwin J. Network analysis, culture, and the problem of agency. Am J Sociol. 1994;99(6):1411-54.

24. Mackenbach JD, Lakerveld J, Van Lenthe FJ, Kawachi I, Mckee M, Rutter H, et al. Neighbourhood social capital: measurement issues and associations with health outcomes. Obes Rev. 2016;17(Suppl 1):96-107.

25. Smith KP, Christakis NA. Social networks and health. Annu Rev Sociol. 2008;34:405-29.

26. Zhang S, de la Haye K, Ji M, An R. Applications of social network analysis to obesity: a systematic review. Obes Rev. 2018;19(7):976-88.

27. Leahey TM, Doyle CY, Xu X, Bihuniak J, Wing RR. Social networks and social norms are associated with obesity treatment outcomes. Obesity. 2015;23(8):1550-4.

28. Kim DA, Hwong AR, Stafford D, Hughes DA, O'Malley AJ, Fowler JH, et al. A randomised controlled trial of social network targeting to maximise population behaviour change. 2015;386(9989):145.

29. de la Haye K, Fluke M, Laney PC, Goran M, Galama T, Chou CP, et al. Inhome obesity prevention in low-income infants through maternal and social transmission. Contemp Clin Trials. 2019;77:61-9.

30. Vassilev I, Rogers A, Kennedy A, Oatley C, James E. Identifying the processes of change and engagement from using a social network intervention for people with long-term conditions. A qualitative study. Health Expect. 2019;22(2):173-82

31. Gesell SB, BesS KD, Barkin SL. Understanding the social networks that form within the context of an obesity prevention intervention. J Obes. 2012;2012:749832

32. Valente TW. Network interventions. Science. 2012;337(6090):49-53.

33. Kozlowski SWJ, Klein KJ. A multilevel approach to theory and research in organizations: contextual, temporal, and emergent processes. In: Klein KJ, Kozlowski SWJ, editors. Multilevel theory, research and methods in organizations: foundations, extensions, and new directions. 1st ed. San Francisco, CA: Jossey-Bass; 2000. p. 3-90.

34. Brug J, Kremers SP, Lenthe FV, Ball K, Crawford D. Environmental determinants of healthy eating: in need of theory and evidence. Proc Nutr Soc. 2008;67:307-16.

35. Bronfenbrenner U. Ecological systems theory: Jessica Kingsley Publishers; 1992.

36. Lomi A, Robins G, Tranmer M. Introduction to multilevel social networks. Soc Networks. 2016;44:266-8.

37. Latkin CA, Knowlton AR. Social network assessments and interventions for health behaviour change: a critical review. Behav Med. 2015:41(3):90-7.

38. Perkins JM, Subramanian SV, Christakis NA. Social networks and health: a systematic review of sociocentric network studies in low- and middleincome countries. Soc Sci Med. 2015;125:60-78.

39. Valente TW, Pitts SR. An appraisal of social network theory and analysis as applied to public health: challenges and opportunities. Annu Rev Public Health. 2017;38:103-18.

40. Huitsing G, Van Duijn MAJ, Snijders TAB, Wang P, Sainio M, Salmivalli C, et al. Univariate and multivariate models of positive and negative networks: liking, disliking, and bully-victim relationships. Soc Networks. 2012;34(4):645-57.
41. Labianca G, Brass DJ. Exploring the social ledger: negative relationships and negative asymmetry in social networks in organizations. Acad Manag Rev. 2006:31:596-614.

42. Dixon-Woods M, Cavers D, Agarwal S, Annandale E, Arthur A, Harvey J, et al. Conducting a critical interpretive synthesis of the literature on access to healthcare by vulnerable groups. BMC Med Res Methodol. 2006;6(1):35.

43. Flemming K. Synthesis of quantitative and qualitative research: an example using critical interpretive synthesis. J Adv Nurs. 2010;66(1):201-17.

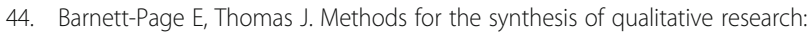
a critical review. BMC Med Res Methodol. 2009;9(1):59.

45. Shakya HB, Christakis NA, Fowler JH. Self-comparisons as motivators for healthy behaviour. Obesity. 2015;23(12):2477-84.

46. Lincoln YS, Lynham SA, Guba EG. Paradigmatic controversies, contradictions and emerging confluences, revisited. The sage handbook of qualitative research. United States: Sage Publications; 2011.

47. Dixon-Woods M, Bonas S, Booth A, Jones DR, Miller T, Sutton AJ, et al. How can systematic reviews incorporate qualitative research? A critical perspective. Qual Res. 2006;6(1):27-44.

48. Alvarado M, Murphy MM, Guell C. Barriers and facilitators to physical activity amongst overweight and obese women in an afro-Caribbean population: a qualitative study. Int J Behav Nutr Phy. 2015;12:97.

49. Kennedy A, Rogers A, Vassilev I, Todorova E, Roukova P, Foss C, et al. Dynamics and nature of support in the personal networks of people with type 2 diabetes living in Europe: qualitative analysis of network properties. Health Expect. 2015;18(6):3172-85.

50. Forthofer M, Burroughs-Girardi E, Stoisor-Olsson L, Wilcox S, Sharpe PA, Pekuri LM. Use of formative research and social network theory to develop a group walking intervention: Sumter County on the move! Eval Program Plann. 2016;58:28-34.

51. Knutsen IR, Foss IC, Todorova E, Roukova P, Kennedy A, Portillo MC, et al. Negotiating diet in networks: a cross-European study of the experiences of managing type 2 diabetes. Qual Health Res. 2017;27(3):299-310.

52. Ali HI, Baynouna LM, Bernsen RM. Barriers and facilitators of weight management: perspectives of Arab women at risk for type 2 diabetes. Health Soc Care Community. 2010;18(2):219-28.

53. Mama SK, McCurdy SA, Evans AE, Thompson DI, Diamond PM, Lee RE. Using community insight to understand physical activity adoption in overweight and obese African American and Hispanic women: a qualitative study. Health Educ Behav. 2015;42(3):321-8.

54. Robertson A, Mullan B, Todd J. A qualitative exploration of experiences of overweight young and older adults. An application of the integrated behaviour model. Appetite. 2014;75:157-64.

55. Sriram U, Morgan E, Graham M, Folta S, Seguin R. Support and sabotage: a qualitative study of social influences on health behaviors among rural adults. J Rural Health. 2018;34:88-97.

56. Daborn C, Dibsall L, Lambert N. Understanding the food related experiences and beliefs of a specific group of low-income men in the UK. Health Educ. 2005:105(2):109-25.

57. Bell R, Smith C, Hale L, Kira G, Tumilty S. Understanding obesity in the context of an indigenous population-a qualitative study. Obes Res Clin Pract. 2017;11(5):558-66.

58. Procter S, Mutrie N, Davis A, Audrey S. Views and experiences of behaviour change techniques to encourage walking to work: a qualitative study. BMC Public Health. 2014;14:868.

59. Vassilev I, Rogers A, Kennedy WM, Koetsenruijter J, Orlando R, et al. Social Network Type and Long-Term Condition Management Support: A Cross-Sectional Study in Six European Countries. PloS One. 2016; 11(8):e0161027.

60. O'Malley AJ, Arbesman S, Steiger DM, Fowler JH, Christakis NA. Egocentric social network structure, health, and pro-social behaviours in a national panel study of Americans. PLoS One. 2012;7(5):e36250.

61. Conklin Al, Forouhi NG, Surtees P, Khaw KT, Wareham NJ, Monsivais P. Socia relationships and healthful dietary behaviour: evidence from over-50s in the EPIC cohort. UK Soc Sci Med. 2014;100:167-75

62. Mötteli S, Siegrist M, Keller C. Women's social eating environment and its associations with dietary behavior and weight management. Appetite. 2017; 110:86-93.

63. Barclay KJ, Edling C, Rydgren J. Peer clustering of exercise and eating behaviours among young adults in Sweden: a cross-sectional study of egocentric network data. BMC Public Health. 2013;13:784. 
64. Winston GJ, Phillips EG, Wethington E, Devine C, Wells M, Peterson JC, et al. Social network characteristics associated with weight loss among black and hispanic adults. Obesity. 2015;23(8):1570-6.

65. Becofsky KM, Shook RP, Sui X, Wilcox S, Lavie CJ, Blair SN. Influence of the source of social support and size of social network on all-cause mortality. Mayo Clin Proc. 2015:90(7):895-902.

66. Rancourt D, Leahey TM, LaRose JG, Crowther JH. Effects of weight-focused social comparisons on diet and activity outcomes in overweight and obese young women. Obesity. 2015;23(1):85-9.

67. Hempler NF, Joensen LE, Willaing I. Relationship between social network, social support and health behaviour in people with type 1 and type 2 diabetes: cross-sectional studies. BMC Public Health. 2016;16:198.

68. Christakis NA, Fowler JH. The spread of obesity in a large social network over 32 years. New Engl J Med. 2007;357(4):370-9.

69. Hong QN, Pluye P, Bujold M, Wassef M. Convergent and sequential synthesis designs: implications for conducting and reporting systematic reviews of qualitative and quantitative evidence. Syst rev. 2017;6(1):61

70. Roberts KA, Dixon-Woods M, Fitzpatrick R, Abrams KR, Jones DR. Factors affecting uptake of childhood immunisation: a Bayesian synthesis of qualitative and quantitative evidence. Lancet. 2002;360(9345):1596-9.

71. Thomas J, Harden A. Methods for the thematic synthesis of qualitative research in systematic reviews. BMC Med Res Methodol. 2008;8:45-54.

72. Schütz A. Collected papers 1. Netherlands: Martinus Nijhoff: The Hague; 1962.

73. Saunders B, Sim J, Kingstone T, Baker S, Waterfield J, Bartlam B, et al. Saturation in qualitative research: exploring its conceptualization and operationalization. Qual Quant. 2018;52(4):1893-907.

74. Schreiber R, Crooks D, Stern PN. Qualitative Meta-analysis. In: Morse JM, editor. Completing a Qualitative Project: Details and Dialogue. Thousand Oaks: CA: Sage; 1997. p. 311-26.

75. Portillo MC, Regaira E, Pumar-Méndez MJ, Mujika A, Vassilev I, Rogers A. Voluntary organizations and community groups as new partners in diabetes self-management and education: a critical interpretative synthesis. Diabetes Educ. 2015;41(5):550-68.

76. McFerran KS, Hense C, Medcalf L, Murphy M, Fairchild R. Integrating emotions into the critical interpretive synthesis. Qual Health Res. 2017;27(1):13-23.

77. Lin S, Melendez-Torres GJ. Critical interpretive synthesis of barriers and facilitators to TB treatment in immigrant populations. Tropical Med Int Health. 2017;22(10):1206-22.

78. Given LM. 100 questions (and answers) about qualitative research. Thousand Oaks: Sage; 2016.

79. Birks M, Mills J. Grounded theory: a practical guide. 2nd ed. London: Sage; 2015.

80. Olshansky EF. Generating theory using grounded theory methodology. In: de Chesnay $M$, editor. Nursing research using grounded theory: qualitative designs and methods in nursing. New York: Springer; 2015. p. 19-28.

81. Bolíbar M. Macro, meso, micro: broadening the 'social' of social network analysis with a mixed methods approach. Qual Quant. 2016;50(5):2217-36.

82. Arias N, Calvo M, Benítez-Andrades J, Álvarez M, Alonso-Cortés B, Benavides C. Socioeconomic status in adolescents: a study of its relationship with overweight and obesity and influence on social network configuration. Int J Env Res Pub He. 2018;15(9):2014.

83. Portillo MC, Kennedy A, Todorova E, Regaira E, Wensing M, Foss C, et al. Interventions and working relationships of voluntary organisations for diabetes self-management: a cross-national study. Int J Nurs Stud. 2017;70: 58-70.

84. Rogers A, Vassilev I, Pumar MJ, Todorova E, Portillo MC, Foss C, et al. Meso level influences on long term condition self-management: stakeholder accounts of commonalities and differences across six European countries. BMC Public Health. 2015;15(1):622.

85. Taplin SH, Anhang Price R, Edwards HM, Foster MK, Breslau ES, Chollette V, et al. Introduction: understanding and influencing multilevel factors across the cancer care continuum. J Natl Cancer I. 2012;2012(44):2-10.

86. Bellotti E. Qualitative networks. Oxford: Routledge; 2015.

87. Rogers, A., Brooks, H., Vassilev, I., Kennedy, A., Blickem, C. and Reeves, D., 2014. Why less may be more: a mixed methods study of the work and relatedness of 'weak ties' in supporting long-term condition selfmanagement. Implementation science, 9(1), p.19.

88. Hanneman RA. Introduction to social network methods. 2000 http://www. faculty.ucr.edu/ hanneman/nettext/. Accessed 7 Feb 2018.
89. Cohen-Cole E, Fletcher JM. Is obesity contagious? Social networks vs. environmental factors in the obesity epidemic. J Health Econ. 2008;27(5): 1382-7.

90. Aral S, Muchnik L, Sundararajan A. Distinguishing influence-based contagion from homophily-driven diffusion in dynamic networks. Proc Natl Acad Sci. 2009;106(51):21544-9.

91. Berkman LF, Glass T, Brissette I, Seeman TE. From social integration to health: Durkheim in the new millennium. Soc Sci Med. 2010;51:843-57.

92. Kawachi I, Berkman LF. Social ties and mental health. J Urban Health. 2001; 78(3):458-67.

93. Nam S, Redeker N, Whittemore R. Social networks and future direction for obesity research: a scoping review. Nurs Outlook. 2015;63:299-317.

94. Kristal AR, Patterson RE, Glanz K, Heimendinger J, Hebert JR, Feng Z, et al. Psychosocial correlates of healthful diets: baseline results from the working well study. Prev Med. 1995;24(3):221-8.

95. Sarkar U, Fisher L, Schillinger D. Is self-efficacy associated with diabetes selfmanagement across race/ethnicity and health literacy? Diabetes Care. 2006; 29(4):823-9.

96. Lazega E, Snijders TA. Multilevel network analysis for the social sciences: theory, methods and applications. New York: Springer; 2015.

97. Degenne A, Forsé M. Introducing social networks. London: Sage Publications; 1999.

98. Bottero W, Crossley N. Worlds, fields and networks: Becker, Bourdieu and the structures of social relations. Cult Sociol. 2011;5:99-119.

99. Lozares C, Martín-Artiles A, López-Roldán P. El tratamiento multiestratégico en la investigación sociológica. Papers Revista de Sociologia. 1998;55:27-43.

100. Sayer A. Method in social science. A realist approach. London: Routledge; 1992.

\section{Publisher's Note}

Springer Nature remains neutral with regard to jurisdictional claims in published maps and institutional affiliations.
Ready to submit your research? Choose BMC and benefit from:

- fast, convenient online submission

- thorough peer review by experienced researchers in your field

- rapid publication on acceptance

- support for research data, including large and complex data types

- gold Open Access which fosters wider collaboration and increased citations

- maximum visibility for your research: over $100 \mathrm{M}$ website views per year

At $\mathrm{BMC}$, research is always in progress.

Learn more biomedcentral.com/submissions 